\title{
Permanent pacing after cardiac transplantation
}

\author{
Christopher D Scott, Janet M McComb, John H Dark, Rodney S Bexton
}

\begin{abstract}
Objective-To determine the need for long-term pacing and optimum mode of pacing in cardiac transplant recipients. Design-(a) A retrospective review of patient records. (b) A prospective study of pacemaker use by 24 hour ambulatory electrocardiography before and after reprogramming to minimise use of pacemakers.
\end{abstract}

Setting-Outpatient clinic, supra-regional cardiopulmonary transplant unit.

Patients-All 21 patients at this centre who had received permanent pacemakers after cardiac transplantation. 18 of 19 survivors completed the prospective part of the study.

Main outcome measure-The presence of pacing during a 24 hour ambulatory electrocardiographic recording (programming: 50 beats/min, rate sensor inactivated).

Results-21 of 191 (11\%) recipients surviving one month or more received permanent pacemakers. The indication was sinus node dysfunction in $13(62 \%)$ and atrioventricular (AV) block in eight (38\%). Patients who paced on follow up 12 lead electrocardiograms declined from $38 \%$ at three months to $10 \%$ at three years after transplantation. After programming to 50 beats/min only five of $18(28 \%)$ patients paced during a 24 hour ambulatory recording. Four of 11 (36\%) recipients who received pacemakers for sinus node dysfunction paced compared with one of seven patients (14\%) paced for AV block. No patient who had a pacemaker before the 16th day after operation continued to pace whereas five of nine implanted later were used longterm.

Conclusion-Only five of 18 (28\%) patients with pacemakers continued to pace long-term. Continued pacing was more common in those with persistent sinus node dysfunction after the second week after operation but the need for long-term pacing was not predictable.

(Br Heart f 1993;69:399-403)

The usual resting heart rate after transplantation has been shown to be about 100 beats/min. ${ }^{12}$ This is due to the absence of autonomic innervation and reflects the dominance of vagal tone in the normal heart. It compares closely with studies of the intrinsic heart rate in pharmacologically denervated hearts. ${ }^{3}$ In the first few weeks after transplantation sinus or junctional bradycardia occur in more than $50 \%$ of recipients. ${ }^{4}$ Donor sinus node dysfunction is the most common cause of bradyarrhythmia, ${ }^{4}$ although atrioventricular block is responsible in some patients. ${ }^{56}$ These early bradyarrhythmias are usually controlled by isoprenaline infusion or temporary epicardial pacing. In some patients bradycardia persists and permanent pacing may be needed. ${ }^{4} 7$

Mackintosh et al suggested that sinus node dysfunction after transplantation indicated a very poor prognosis. ${ }^{8}$ This report led to the initial adoption of an aggressive early pacing policy at this and other centres. ${ }^{9}$

Some authors have recently advocated complex modes of pacing in transplant patients who require permanent pacemakers. ${ }^{10-12}$ It was our impression, however, that permanent pacemakers are often used for a short period after transplantation and complex pacing systems might be unnecessary. This study was therefore undertaken to assess the frequency and predictability of long-term pacing requirements in patients who had received permanent pacemakers after transplantation.

\section{Patients and methods}

Between May 1985 and March 1992, 218 adults underwent orthotopic heart transplantation at this centre and 191 survived at least one month. The operative procedure was as described by Lower et al. ${ }^{13}$ Temporary epicardial atrial and ventricular pacing wires were placed at the time of operation in each patient and were removed around day 21 after operation.

In the early stages of our transplant programme VVI pacemakers were implanted between days 8 and 21 on a prophylactic basis when the resting heart rate was below 70 beats/min. Subsequently physiological and rate responsive systems were used as it was thought that these would improve exercise tolerance. The programmed rates were chosen to mimic heart rates achieved by other transplant patients without sinus or atrioventricular node dysfunction. A further review of our pacing policy was undertaken after an earlier study. ${ }^{14}$ Thereafter pacemakers were only implanted for symptomatic bradyarrhythmias that persisted after the end of the third postoperative week. 
RETROSPECTIVE REVIEW

The clinical records of all patients with permanent pacemakers were examined. The original indication for pacing, the implantation time, pacemaker type, and programming were noted. Treatment with cardioactive drugs, including preoperative amiodarone was recorded. The ischaemic time, donor age, and episodes of rejection were recorded for all transplant recipients. Complications related to pacemakers were noted. Resting 12 lead electrocardiograms taken at three monthly intervals during routine follow up were examined.

\section{PROSPECTIVE STUDY}

A 24 hour ambulatory electrocardiogram was performed on 18 of 19 surviving patients. In 16 patients a recording was made with the variables programmed at the time of implantation. In those patients in whom pacemaker activity was detected during the initial recording the pacemaker was reprogrammed to 50 beats/min with the rate sensor inactivated if present. The 24 hour ambulatory electrocardiogram was then repeated. Two patients had their pacemaker reprogrammed in this way to minimise its use before the initial recording.

\section{STATISTICAL ANALYSIS}

Statistical analyses were performed with Student's $t$ test or Mann-Whitney $U$ test. Results are expressed as mean (SD).

\section{Results}

RETROSPECTIVE STUDY

The table summarises the results. Of 191 adult heart transplant recipients surviving at least one month, 21 received permanent pacemakers. For 13 patients $(62 \%)$ the indication for pacing was sinus node dysfunction, manifest as sinus bradycardia in 10 cases with rates of between 30 and 60 beats $/ \mathrm{min}$. The other three patients in this group had sinus arrest with nodal escape rhythm. Eight patients $(38 \%)$ had pacemakers because of atrioventricular block. Six of these had second or third degree block and two had atrial flutter with variable block.

The mean interval between transplantation and permanent pacing was 19.4 days (range eight to 90 days). Only one pacemaker was implanted after the first postoperative month. This patient had no early bradyarrhythmias. There was evidence of the bradycardia-tachycardia syndrome on a 24 hour ambulatory recording. This patient died four months after transplantation from infection and renal failure and could not therefore be included in the prospective part of the study. Four patients had taken amiodarone before transplantation, each at a dose of $200 \mathrm{mg}$ daily, for between one and 36 months. Isoprenaline was used in all subjects but only in the immediate postoperative period. No other cardioactive drugs were prescribed.

Ventricular pacemakers were implanted in 15 patients (eight rate responsive), atrial pacemakers in three (all rate responsive) and dual chamber in three (two rate responsive). The VVI pacemakers were programmed to 70 beats $/ \mathrm{min}$, the DDD to 90 beats $/ \mathrm{min}$. The rate responsive pacemakers were all activity sensing units and were programmed to a minimum rate of 80 beats $/ \mathrm{min}$ and a maximum rate of 130 beats $/ \mathrm{min}$.

There was no difference between the operative ischaemic time in those patients who subsequently required permanent pacemakers and those who did not $(169(40) \mathrm{min}, \mathrm{n}=21 v$ 169 (46) $\min , \mathrm{n}=170 ; \mathrm{p}=0.99$ ) or between the donor ages $(31.9(9.5) v 29.6(9.3) ; \mathrm{p}=$ $0.34)$. The patients with pacemakers had a mean of 0.41 episodes of rejection (moderate, Billingham classification ${ }^{15}$ ) in the first month

\begin{tabular}{|c|c|c|c|c|c|c|c|c|c|c|c|c|}
\hline \multirow[b]{2}{*}{ No } & \multirow{2}{*}{$\begin{array}{l}\text { Implantation } \\
\text { day after } \\
\text { operation }\end{array}$} & \multirow[b]{2}{*}{ Mode } & \multirow[b]{2}{*}{ Indication } & \multicolumn{6}{|c|}{ Months after operation } & \multirow[b]{2}{*}{ Tape 1} & \multirow[b]{2}{*}{ Tape 2} & \multirow[b]{2}{*}{ Comments } \\
\hline & & & & 3 & 6 & 9 & 12 & 24 & 36 & & & \\
\hline 1 & 18 & VVI & SND & - & - & - & - & - & - & & - & Paces only at night tape 2 \\
\hline 2 & 14 & VVI & SND & - & - & - & - & - & - & + & + & \\
\hline 3 & 8 & VVI & AVB & - & - & - & - & - & - & - & & \\
\hline 4 & 9 & VVI & SND & + & - & - & - & - & - & & & Not in prospective study \\
\hline 5 & 15 & VVI & AVB & - & - & - & - & - & - & - & & \\
\hline 6 & 19 & DDD & SND & + & + & + & + & + & + & + & + & $\begin{array}{l}\text { Upgraded form VVI because of } \\
\text { pacemaker syndrome } \\
\text { Died at } 7 \text { months }\end{array}$ \\
\hline 7 & 9 & VVI & AVB & + & - & - & & & & & & \\
\hline 8 & 17 & VVI & SND & - & - & - & - & - & - & - & & \\
\hline 9 & 16 & VVIR & SND & - & + & - & - & - & - & - & & \\
\hline 10 & 9 & VVIR & AVB & + & - & - & - & - & - & + & - & \\
\hline 11 & 15 & VVIR & AVB & - & - & - & - & - & - & + & - & \\
\hline 12 & 20 & VVIR & SND & + & - & + & + & + & & + & + & $\begin{array}{l}\text { Unable to tolerate VVI pacing } \\
\text { (chronotropic incompetence) }\end{array}$ \\
\hline $\begin{array}{l}13 \\
14\end{array}$ & $\begin{array}{l}10 \\
90\end{array}$ & $\begin{array}{l}\text { DDDR } \\
\text { VVIR }\end{array}$ & $\begin{array}{l}\text { SND } \\
\text { SND }\end{array}$ & + & + & + & + & - & & + & - & $\begin{array}{l}\text { Late sinus dysfunction, died } \\
\text { renal failure/ infection. }\end{array}$ \\
\hline 15 & 12 & VVIR & AVB & - & - & - & - & - & & + & - & \\
\hline 16 & 14 & VVIR & SND & - & - & - & - & & & - & & \\
\hline 17 & 15 & VVIR & AVB & - & - & & - & & & + & - & \\
\hline 18 & 26 & AAIR & SND & - & + & + & - & & & + & + & \\
\hline 19 & 25 & AAIR & SND & - & - & - & & & & + & - & Pacemaker induced AVNRT \\
\hline 20 & 21 & DDDR & AVB & + & + & + & & & & + & + & \\
\hline 21 & 25 & AAIR & SND & + & - & & & & & + & - & \\
\hline
\end{tabular}

ECG, electrocardiogram indicating pacing; SND, sinus node dysfunction; AVB, +, electrocardiographic evidence of pacing; electrocardiographic atrioventricular block; AVNRT, AV node reentrant tachycardia; evidence of no pacing; tape 1, 1st ambulatory electrocardiogram; tape 2, 2nd ambulatory electrocardiogram after reprogramming. 
Number of patients pacing (hatched area) and not pacing (clear area) based on resting 12 lead electrocardiograms at the indicated times after transplantation.

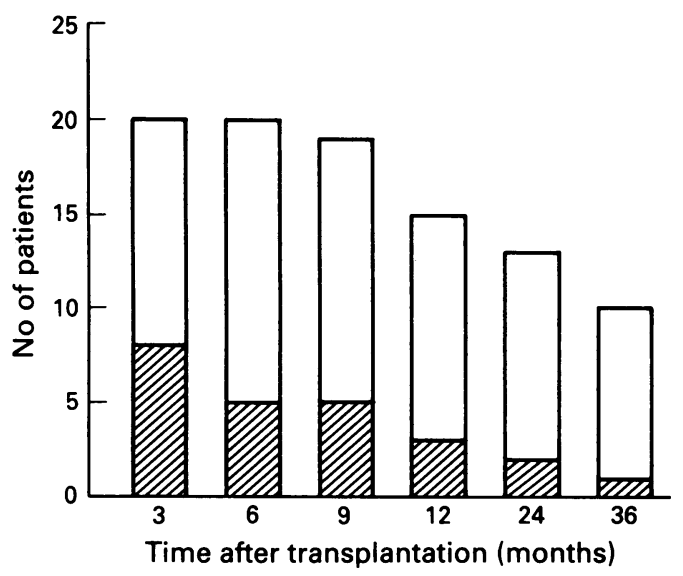

after operation compared with 0.32 episodes for other transplant recipients. This difference was not statistically significant $(\mathrm{p}=0 \cdot 18)$.

The frequency of pacing on resting 12 lead electrocardiograms declined progressively with time after transplantation from $8 / 20$ $(40 \%)$ at three months to $1 / 10(10 \%)$ at 36 months (figure).

There were two episodes of lead displacement during 350 endomyocardial biopsy procedures with a ventricular lead in place. On both occasions the pacemaker had been implanted within the preceding 14 days and both leads were repositioned without incident. No atrial leads were displaced during 73 procedures with atrial leads in situ.

PROSPECTIVE STUDY

During the single 24 hour ambulatory electrocardiographic recording before reprogramming 12 of 18 patients paced intermittently. The rest were not pacing at all. The presence of any pacing was clearly related to the programming of the pacemaker implanted. Only one of five patients with a simple VVI device paced whereas 10 of 13 rate responsive pacemakers were used at some stage, often at rates of greater than 100 beats $/ \mathrm{min}$.

After reprogramming only five patients continued to be paced on a further single 24 hour ambulatory electrocardiographic recording. Two of these used their pacemaker only at night. One of the patients with a rate responsive pacemaker who paced intermittently on the initial recording was unable to tolerate inactivation of the rate sensor. The original indication in this patient was sinus node dysfunction and the underlying rhythm was sinus at 60 beats/min. Informal exercise testing produced no increase in heart rate and the patient experienced extreme fatigue and presyncope. The pacemaker was therefore programmed to $50-130$ beats/min VVIR Ambulatory monitoring showed continued intermittent pacing. No other patient reported any adverse effects from reprogramming.

After reprogramming one of seven (14\%) subjects paced for atrioventricular block was pacing whereas 4 of $11(36 \%)$ with sinus node dysfunction continued to pace.

\section{Discussion}

\section{LIMITATIONS OF THE STUDY}

The patients included in this study were identified retrospectively by the implantation of permanent pacemakers. Other patients with the rhythm disorders discussed who did not receive permanent pacemakers were therefore excluded. Although 12 lead electrocardiograms were available for all patients at the specified times after transplantation the ambulatory recordings were performed at variable times between three and 65 months. Single 24 hour ambulatory electrocardiograms provide insufficient data from which to be certain that the pacemakers are no longer required. Miyamoto et al however removed an infected pacemaker in one of their patients after 24 hours of ambulatory monitoring showed that there had been no pacing. ${ }^{5}$ Our data and previous electrophysiological studies, suggest improvements in sinus node function with time, and give some support to the conclusion that the pacemakers were no longer needed. Exercise tolerance was not formally assessed. We cannot therefore deny that some benefit results from pacing in patients who have no absolute requirement.

\section{INDICATIONS FOR PERMANENT PACING}

Sinus node dysfunction

Sinus node dysfunction after transplantation has been widely reported and studied by electrophysiology. ${ }^{7816}$ The incidence varies from $50 \%^{8}$ early after transplantation (four to 24 days) to $29 \%^{16}$ in long-term survivors (four to 14 months).

The natural history of sinus node dysfunction during the first year after transplantation has not been described. It is clearly of importance when attempting to assess the need for long-term pacing in these patients. Heinz et al reported that donor sinus arrest with or without junctional escape rhythm was predictive of persistent sinus node dysfunction, ${ }^{7}$ but electrophysiological indices were unhelpful.

Our overall implantation rate of $11 \%$ compares with rates of between $4 \%^{5}$ and $24 \%^{7}$ reported by other centres. A report by Mackintosh et al published three years before the start of the transplant programme at this centre raised considerable concern about the prognosis in recipients with sinus node dysfunction. ${ }^{8}$ Four of five such patients died within four months of transplantation compared with none of five other patients studied. Only one of these deaths was shown to be due to bradycardia but as a result of this study, a low threshold for implanting permanent pacemakers was adopted at this and other centres. ${ }^{9}$ In two large series the indication for pacing in $35 \%{ }^{5}$ and $61 \%^{9}$ of subjects was symptom free bradyarrhythmias including sinus bradycardia.

The aetiology of persistent sinus node dysfunction after transplantation is unknown. Some authors have reported an association with prolonged operative ischaemic time ${ }^{4}$ but we and others ${ }^{9}$ have not confirmed these findings. Heinz and colleagues found an asso- 
ciation between transient but not persistent sinus dysfunction and prolonged ischaemic time. ${ }^{7}$ DiBiase et al linked abnormalities of the sinus node artery with sinus dysfunction. ${ }^{9}$

\section{Atrioventricular block}

There are no published data on the frequency and natural history of atrioventricular block after transplantation. Although it was common in one series, ${ }^{17}$ in most it is much less common than sinus node dysfunction. Bexton et al found no evidence of atrioventricular block during electrophysiological studies in 14 patients at between four and 14 months after transplantation. ${ }^{18}$ Miyamoto et al described a slow ventricular response to atrial fibrillation and flutter in $1 \%(4 / 401)$ of transplant recipients. ${ }^{5}$ This resolved within 20 days and permanent pacing was not required. In the series published by DiBiase et al $10 \%$ of pacemakers were implanted for various degrees of atrioventricular block ${ }^{9}$ compared with $38 \%$ in our series. Our limited data from 12 lead electrocardiograms suggest that atrioventricular block after transplantation usually resolves within three to six months.

\section{TIMING OF PACING}

In this study no patient who received a pacemaker before day 15 after operation continued to need a pacemaker long-term. Some authors have advocated pacing at between seven and 10 days after transplantation. ${ }^{19}$ This policy, however, may lead to unnecessary implantations particularly in patients with sinus node dysfunction that may continue to resolve throughout the first month. ${ }^{7}$

If clinical or electrophysiological variables (such a those suggested by Heinz et al could be confirmed as reliable indicators of subsequent sinus node function then the optimum timing of pacemaker implantation would be more evident. Successful pharmacological treatment of these bradyarrhythmias with terbutaline $^{20}$ or theophylline $e^{21}$ has been reported and would be particularly suitable if the problem was known to be temporary.

In the absence of such clear indicators the optimum timing of pacing must reflect a compromise between the advantages of early pacemaker implantation (increased mobility and earlier hospital discharge) and the risks of an invasive procedure in an immunocompromised patient. Epicardial pacing wires are usually removed on day 21 after operation at this centre. Unless other complications delay discharge a decision regarding permanent pacing is usually made at this point.

\section{THE NEED FOR LONG-TERM PACING}

In this study five of 18 (28\%) pacemaker recipients studied by ambulatory monitoring paced long-term while programmed to 50 beats $\mathrm{min}$. The reported frequency of longterm pacing in transplant recipients varies considerably. In several series between $57 \%$ and $100 \%$ of recipients with pacemakers required long-term pacing but the programming details are not clearly described and ambulatory monitoring was not used in all of these studies. ${ }^{7919}$ Loria et al reported that neither of their two pacemaker recipients continued to pace long-term when the systems were reprogrammed to 60 beats $/ \mathrm{mm} .^{12}$

\section{LATE IMPLANTATION PACEMAKER}

One of 21 pacemakers in our series was implanted after the first postoperative month. There are several reports of late bradyarrhythmias requiring permanent pacing ${ }^{59}$ ${ }^{22-24}$ although the incidence is low compared with the immediate period after operation. ${ }^{9}$ Both sinus dysfunction and atrioventricular block have been described and accelerated graft coronary disease has been implicated in some cases. ${ }^{94}$ The paroxysmal nature of the bradyarrhythmias in our patient and the unpredictability in the onset of these arrhythmias also suggests a different aetiology from early bradyarrhythmias.

\section{MODE OF PACING}

The optimum mode of pacing in recipients of cardiac transplants is controversial. Physiological pacing is advocated by some authors ${ }^{10-12}$ and its advantages in non-transplant patients who need long-term pacing are clearly established. ${ }^{25-27}$ The haemodynamic benefits of atrial pacing in transplant recipients have been confirmed despite abnormal atrial morphology, characteristic of the transplanted heart. ${ }^{28}$ Many transplant recipients, however, may require relatively short-term pacing. For this reason and because of concern about the subsequent development of atrioventricular block some large centres advocate ventricular pacing in all cases. ${ }^{59}$

In patients receiving atrial pacemakers the integrity of the atrioventricular conduction system is routinely tested by incremental atrial pacing and measurement of the Wenckebach point. There is no evidence to support concerns about the subsequent development of atrioventricular block in these patients.

In general the prescription of a rate adaptive pacemaker should be based on observed chronotropic incompetence. The chronotropic response to exercise is abnormal in all transplant recipients ${ }^{29}$ because of autonomic denervation. The resting heart rate is high but there is a delayed and blunted response of heart rate to exercise. There is, however, no evidence that rate adaptive pacing can improve on the chronotropic response of the normal sinus node after transplantation. Although the theoretical benefits of a recipient atrium sensing system are clear, ${ }^{10}$ the high incidence of recipient sinus node dysfunction may limit the general applicability of this technique. ${ }^{16}$ It also remains to be shown whether there is a significant clinical advantage.

The need for long-term pacing in transplant recipients receiving pacemakers soon after transplantation is infrequent. Those with sinus node dysfunction are more likely to require long-term pacing than those with atrioventricular block.

There are, however, at present no clear 
prognostic indicators of subsequent pacing requirements in those with persistent bradyarrhythmias after the third week. A pacing system suitable for long-term use should therefore be selected. We recommend that implantation is delayed until at least 21 days after transplantation and until the patient is otherwise ready for discharge from hospital in order to reduce the frequency of unnecessary implantations.

The mode of pacing should be selected on an individual basis. Although there is no specific evidence of the superiority of physiological or rate responsive pacing in transplant recipients, the advantages in other patients are clearly established. Physiological pacing should probably be used where possible and rate adaptive systems used for those patients with confirmed chronotropic incompetence.

1 Alexopoulos D, Yusuf S, Bostock J, Johnston JA, Sleight $P$, Yacoub M. The 24 hour heart rate behaviour in long $\mathrm{P}$, Yacoub M. The 24 hour heart rate behaviour in long term survivors

2 Scott CD, McComb JM, Dark JH. Heart rate and late mortality in cardiac transplant recipients. Eur Heart $\mathcal{F}$ 1993; (in press)

3 Jose AD. Effect of combined sympathetic and parasympathetic blockade on heart rate and cardiac function in man. Am F Cardiol 1966;18:476-8.

4 Jacquet L, Ziady G, Stein K, et al. Cardiac rhythm disturbances early after orthotopic heart transplantation: prevalence and clinical importance of the observed abnormalities. F Am Coll Cardiol 1990;16:832-7.

5 Miyamoto Y, Curtiss EI, Kormos RL, Armitage JM, Hardesty RL, Griffith BP. Bradyarrhythmias after heart transplantation. Circulation 1990;82:(suppl IV)313-7.

6 Dodinot B, Costa AB, Godenir JP, et al. AV block after cardiac transplantation-pacing modes selection cardiac transplantation-pacin
[abstract]. $P A C E$ 1991;14:682.

7 Heinz G, Ohner T, Laufer G, Gasic S, Laczkovics A Clinical and electrophysiological correlates of sinus node dysfunction after orthotopic heart transplantation. Chest 1990;97:890-5.

8 Mackintosh AF, Carmichael DJ, Wren C, Cory-Pearce R, English TAH. Sinus node function in the first three weeks after cardiac transplantation. Br Heart $\mathcal{f} 1982 ; 48$ : 584-8.

9 DiBiase A, Tse TM, Schnittger I, Wexler L, Stinson EB, Valantine HA. Frequency and mechanism of bradycardia in cardiac transplant recipients and need for pacemakers. Am $\mathcal{F}$ Cardiol 1991;67:1385-9.

10 Osterholzer G, Markewitz A, Anthuber M, Kemkes BH. An example of how to pace a patient with a heart transplantation. $\mathcal{F}$ Heart Transplant 1988;7:23-5.
11 Markewitz A, Kemkes BH, Reble B, et al. Particularities of dual chamber pacemaker therapy in patients after orthotopic heart transplantation. PACE 1987;10: orthotop

12 Loria $\mathrm{K}$, Salinger $\mathrm{M}$, McDonough $\mathrm{T}$, Frohlich $\mathrm{T}$, Arentzen C. Activitrax AAIR pacing for sinus node dysfunction after orthotopic heart transplantation: an initial report. $\mathcal{F}$ Heart Transplant 1988;7:380-4.

13 Lower RR, Stofer RC, Shumway NE. Homovital transplantation of the heart. $\mathcal{F}$ Thorac Cardiovasc Surg 1961 41:196-202.

14 Scott CD, Omar I, McComb JM, Dark JH, Bexton RS Long term pacing in heart transplant recipients is usually unnecessary. $P A C E$ 1991;14:1792-6.

15 Billingham ME. Diagnosis of cardiac rejection by endomyocardial biopsy. If Heart Transplant 1981;1: 25-30.

16 Bexton RS, Nathan AW, Hellestrand KJ, et al. Sinoatrial function after cardiac transplantation. $\mathcal{F} \mathrm{Am}$ Coll Cardiol 1984;3:712-23.

17 Dodinot B, Costa AB, Godenir JP, et al. AV block after cardiac transplantation-pacing modes selection cardiac transplantation-pacing

18 Bexton RS, Nathan AW, Hellestrand KJ, et al. Electrophysiological abnormalities in the transplanted human heart. Br Heart $\mathcal{F}$ 1983;50:555-63.

19 Payne ME, Murray KD, Watson KM, et al. Permanen pacing in heart transplant recipients: underlying cause and long term results. F Heart Transplant 1991;10 738-42.

20 Cook LS, Will KR, Moran J. Treatment of junctional rhythm after heart transplantation with terbutaline. $\mathscr{f}$ Heart Transplant 1989;8:342-4.

21 Redmond JM, Zehr K, Gillinov MA, et al. Use of theophylline for treatment of prolonged sinus node dysfunction in human orthotopic heart tion in human orthotopic heart trans. $\mathcal{f}$ Heart Transplant 1992;11:203.

22 Addonizio LT, Hsu DT, Smith CR, Gersony WM, Rose EA. Late complications in paediatric cardiac transplant EA. Late complications in paediatric cardiac transplat
recipients. Circulation 1990;82 (suppl IV):295-301.

23 Couetil S, Mihaileanu T, Lavergne R et al. Total excision of the recipient atria in orthotopic heart transplantation as a new clinical procedure: technical consideration an early results [abstract]. $\mathcal{F}$ Heart Transplant 1991;10:179.

24 Berke DK, Graham AF, Schroeder JS, Harrison DC Arrhythmias in the denervated transplanted human heart. Circulation 1973;47 (suppl III): 112-5.

25 Perrins EJ, Morley CA, Chan SL, Sutton R. Randomised controlled trial of physiological and ventricular pacing. Br Heart F 1983;50:112-7.

26 Ebagosti A, Genoun M, Saadjian A, et al. Long term follow up of patients treated with VVI pacing and sequenlow pacing with special reference to VA retrogential pacing with special reference

27 Fisher M, Kase CS, Stelle B, Mills RM. Ischaemic stroke after cardiac pacemaker implantation in sick sinus synafter cardiac pacemaker implant

28 Midei MG, Baughman KL, Achuff SC, Walford GD, Baumgartner W, Brinker JA. Is atrial activation beneficial in heart transplant recipients? $\mathcal{f} \mathrm{Am}$ Coll Cardio 1990;16:1201-4

29 Pope SE, Stinson EB, Daughters GT, Schroeder JS Ingels NB, Alderman EL. Exercise response of the denervated heart in long term cardiac transplant recipients. Am $\mathcal{F}$ Cardiol 1980;46:213-8. 